\title{
The effects of dietary herbs and coral mineral complex on growth performance, nutrient digestibility, blood characteristics and meat quality in finishing pigs
}

\author{
Y. Wang, Y.J. Chen, J.H. Cho, J.S. Yoo, Q. Wang, Y. Huang, \\ H.J. Kim and I.H. Kim ${ }^{1}$
}

Department of Animal Resource and Science, Dankook University

\#29 Ansedong, Cheonan, Choognam, 330-714, Korea

(Received 11 January 2007; revised version 1 September 2007; accepted 6 September 2007)

\begin{abstract}
Eighty crossbred pigs of initial mean body weight $58 \mathrm{~kg}$ were used to evaluate the effect of supplemental herbs and coral mineral complex (HC) on growth performance, nutrient digestibility, blood characteristics and meat quality in a 8 weeks growth trial. Pigs were randomly allocated to 4 treatments, which comprised: 1 . control, 2 . HC $0.05 \%$, 3. HC $0.1 \%$, and 4 . $\mathrm{HC} 0.2 \%$, respectively (4 pigs/pen, 5 replicates/treatment). Gain/feed linearly increased during week 4-8 $(\mathrm{P}<0.05)$ and overall period $(\mathrm{P}<0.10)$ with increasing $\mathrm{HC}$ level. Digestibility of DM and $\mathrm{N}$ during week $0-4$ increased linearly with an increasing $\mathrm{HC}$ level $(\mathrm{P}<0.005)$. Serum IgG concentrations linearly increased with the increase of $\mathrm{HC}$ supplementation $(\mathrm{P}<0.01)$. Cortisol concentrations tended $(\mathrm{P}<0.10)$ to decrease linearly with increasing level of HC. The linear reduction of subjective scores for marbling $(\mathrm{P}<0.01)$ and firmness $(\mathrm{P}<0.01)$ of the longissimus muscle were observed. In conclusion, supplementation of $\mathrm{HC}$ improved feed efficiency and increased IgG and cortisol concentration in serum.
\end{abstract}

KEY WORDS: herb, coral, IgG, cortisol, meat quality, pigs

\section{INTRODUCTION}

In recent years, the use of medical herbs are being accepted and used increasingly by either human or animals. Herbs are mainly derived from natural

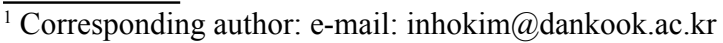


products, with more than $80 \%$ from plants. They already have a long history that used medicinally in Asia countries since antiquity. A variety of herbs is widely utilized to treat the diseases of human and animals. This is because herbs are easy and cheap to prepare, and are effective with fewer side effects during treatment of diseases (Jian and Wu, 2003). Semen Zizyphi spinosae, pollen pini, cortex mori and radix Achyranthis bidentatae, the active components of the used herb-mix, are known for their sedative and anxiolytic properties (Mdidea, 1997; Choi, 2007). Herbs have many potential clinical and therapeutic applications in the modern medical setting. They also are rich in a wide variety of nutrients and are new additives for livestock feed, due to they can be used as attractants to increase feed intake, improve growth rate and feed utilization (Zheng and Wang, 2001). In addition, according to the medicinally effects of herbs, large amount of previous studies investigated the influence of herbs on animal's immunity and observed positive effects (Chiang et al., 2003). However, there were still several inconsistent reports that suggested such positive herbs effects can't be observed (Hermann et al., 2003). It should indicate that the different results may mainly ascribe to different sources and ingredients of herbs used by researchers. Therefore, it is necessary to evaluate certain herb products practically.

Coral mineral complex (HC) is a source of organic minerals powder from fossilized corals. These corals contain a natural balanced mixture of over 74 minerals, which is rich in calcium, magnesium and all the trace minerals needed by the human body. The organic origin of the coral minerals guarantees that they are well absorbed by the body, because of its natural ability to become ionic upon contact with moisture. This ability to combined with the full spectrum, organic formation, makes coral one of the most absorbable forms of minerals (Mcvitamins, 2000). The use of organic mineral in animal feeds brings a number of advantages for performance and meat quality (Mahan et al., 1999). Additionally, some researchers reported that magnesium (one of the components of coral mineral) is able to reduce plasma corticosteroids stimulation (Kietzmann and Jablonski, 1985).

There are limited research about dietary of herbs and coral mineral complex in finishing pigs. It was hypothesized that these two feed additives either alone or in combinations would enhance the performance by reducing the stress in pigs. Also, less stress in pig can reduce the chance of PSE (pale, soft and exudative) and DFD (dark, firm and dry) pork thereby improving meat quality (Warriss, 1993). Measuring blood parameters could be useful to detect the anti-stress effect of herbs and coral mineral complex. Therefore, the aim of this study was to evaluate: 1. the effects of $\mathrm{HC}$ on finishing pig performance, nutrient digestibility, immune blood characteristics and meat quality and 2 . whether pig stress can be decreased by dietary HC supplementation. 


\section{MATERIAL AND METHODS}

\section{Source and composition of herbs and coral mineral complex}

The herbs and coral mineral complex contained 40\% herbs: semen Zizyphi spinosae (Spina Date Seed) 10\%, pollen pini 5\%, cortex mori (white mulberry root-bark) 5\%, semen Plantaginis (Plantago asiatica) 5\%, radix Achyranthis bidentatae (Achyranthes root) 5\%, Rhizoma Acori tatarinowii (Grassleaf Sweelflag Rhizome) 5\% and herb Capsellae (shepherds purse herb) 5\%, 50\% coral mineral (\%: $\mathrm{Ca} 22, \mathrm{P} 2, \mathrm{Mg} \mathrm{3}, \mathrm{Mn} 0.5, \mathrm{Na} 2, \mathrm{Cl} 1, \mathrm{Zn} \mathrm{0.5,} \mathrm{Fe} \mathrm{1.5,} \mathrm{Se} 1$ and other 16.5) and $10 \%$ carrier (Manufacturer's specification).

\section{Experimental design, animals, housing and diets}

The experimental protocol was approved by the Animal Care and Use Committee of Dankook University. A total of 80 crossbred (Landrace $\times$ Yorkshi re $\times$ Duroc) pigs $(58.06 \pm 1.47 \mathrm{~kg}$ of $\mathrm{BW})$ were allotted to four dietary treatments on the basis of initial BW according to a completely randomized design, 4 pigs ( 2 barrows, 2 gilts $)$ per pen $(1.8 \mathrm{~m}$ width $\times 1.8 \mathrm{~m}$ length $)$ and 5 replications per treatment. All the pigs were housed on a concrete, slatted floor in an environmentally-controlled room, which target room temperature and humidity was maintained at $22^{\circ} \mathrm{C}$ and $60 \%$, respectively. The experimental period lasted 8 weeks.

Dietary treatments include: 1 . CON (basal diet); 2 . HC 0.05 (basal diet $+0.05 \%$ $\mathrm{HC}$ ); 3 . HC 0.1 (basal diet $+0.1 \% \mathrm{HC}$ ) and 4. $\mathrm{HC} 0.2$ (basal diet $+0.2 \% \mathrm{HC}$ ). $\mathrm{HC}$ were replaced with rice bran in the diets.

Two finisher diets (Table 1) were formulated to meet or exceed of NRC (1998) recommendations for all nutrients and fed in meal form. Each pen was equipped with a one-sided self-feeder and a nipple waterer to allow ad libitum access to feed and water throughout the experimental periods.

\section{Sampling and measurements}

Body weight and feed intake were measured at the end of week 0,2, 4 and 8 to determine average daily gain (ADG), average daily feed intake (ADFI) and gain/feed. Total tract apparent digestibility (CTTAD) for DM and N were determined at the end of week 4 and 8 . Pigs were fed diets containing chromic oxide $(0.2 \%)$ as an indigestible marker, for 7 days prior to the collection day, and fresh faecal grab samples were obtained once daily from at least two pigs in each pen. All the faecal samples, as well as feed samples were stored in refrigerator until analysis. Before chemical analysis, faecal 
Table 1. Composition of experimental diets (as-fed basis) ${ }^{1}$

\begin{tabular}{|c|c|c|}
\hline Item & $\begin{array}{c}\text { Early finisher } \\
\text { Period }\end{array}$ & $\begin{array}{l}\text { Late finisher } \\
\text { period }\end{array}$ \\
\hline \multicolumn{3}{|l|}{ Ingredient, $\%$} \\
\hline ground maize & 59.93 & 67.45 \\
\hline soyabean meal & 23.75 & 18.14 \\
\hline rice bran & 5.00 & 5.00 \\
\hline molasses & 4.00 & 5.00 \\
\hline animal fat & 2.61 & 2.00 \\
\hline rapeseed meal & 2.00 & - \\
\hline phosphorus defluoronized & 1.16 & 1.12 \\
\hline calcium carbonate & 0.44 & 0.68 \\
\hline L-lysine, $78 \%$ & 0.34 & 0.20 \\
\hline salt & 0.15 & 0.15 \\
\hline vitamin premix $^{2}$ & 0.25 & 0.15 \\
\hline mineral premix $^{3}$ & 0.10 & 0.05 \\
\hline DL-methionine, $98 \%$ & 0.10 & \\
\hline choline chloride, $60 \%$ & 0.08 & 0.04 \\
\hline L-threonine, $98 \%$ & 0.09 & 0.02 \\
\hline \multicolumn{3}{|l|}{ Chemical composition $^{4}$} \\
\hline $\mathrm{ME}, \mathrm{MJ} / \mathrm{kg}$ & 13.44 & 13.36 \\
\hline crude protein, $\%$ & 17.72 & 14.80 \\
\hline lysine, $\%$ & 1.02 & 0.89 \\
\hline $\mathrm{Ca}, \%$ & 0.70 & 0.74 \\
\hline $\mathrm{P}, \%$ & 0.59 & 0.54 \\
\hline \multicolumn{3}{|c|}{$\begin{array}{l}1 \text { early finisher period }=\text { wk } 0 \text { to } 4 \text {, late finisher period }=\text { wk } 4 \text { to } 8 \text {, and overall }=\text { wk } 0 \text { to } 8 \\
2 \text { supplied per kg diet, IU: vit. A 4,000, vit. } \mathrm{D}_{3} 800 \text {, vit. E } 171 \text {; mg: vit. } \mathrm{K} 2 \text {, vit. } \mathrm{B}_{2} 4 \text {, vit. } \mathrm{B}_{6} 1 \text {, } \\
\text { pantothenic acid } 11 \text {, niacin } 20 \text { and biotin } 0.02 ; \mu \mathrm{g} \text { : vit. } \mathrm{B}_{12}, 16 \\
3 \text { supplied per kg diet, mg: } \mathrm{Cu} 220, \mathrm{Fe} 175, \mathrm{Zn} 191, \mathrm{Mn} 89 \text {, I } 0.3 \text {, Co } 0.5 \text { and Se } 0.4 \\
4 \text { calculated values }\end{array}$} \\
\hline
\end{tabular}

samples were thawed and dried at $70^{\circ} \mathrm{C}$ for $72 \mathrm{~h}$ and subsequently ground to pass through a 1-mm screen. All the feed and faecal samples were analysed for DM and $\mathrm{N}$ according to the AOAC procedures (1995) while chromium was determined by UV absorption spectrophotometry (Shimadzu, IJV-1201, Japan) according to the methods of Fenton and Fenton (1979). Nitrogen was measured using a Kjeltec 2300 Analyzer (Foss Tecator AB, Hoeganaes, Sweden).

Blood samples were collected from cervical vein into both $\mathrm{K}_{3}$ EDTA vacuum tubes and clot activator vacuum tubes (Becton Dickinson Vacutainer Systems, Franklin Lakes, NJ, USA) from 2 pigs in each pen at the beginning and end of the experiment. Lymphocytes count in whole blood and cortisol and $\mathrm{IgG}$ in serum were measured; lymphocytes - using the automatic blood analyzer (ADVIA 120, Bayer, USA), serum parameters (cortisol and $\operatorname{IgG}$ ) - using a radioimmunoassay kit (Diagnostic Products Co., USA) and Cobra 5010 Quantum (Diagnostic Products Co., USA), respectively.

Pigs were slaughtered at a local commercial slaughter house. After chilling at $2{ }^{\circ} \mathrm{C}$ for at least $24 \mathrm{~h}$, one $2.54-\mathrm{cm}$-thick longissimus muscle (LM) sample was 
removed at the 10th rib (right side of carcass) and allowed to bloom for $30 \mathrm{~min}$. Subjective colour, marbling, and firmness scores on the LM were evaluated on the cut surface following the procedures described by NPPC (1991). Colour, marbling and firmness were scored by sensory panel consisted of 11 trained panelists, using a 5 -point scale $(1=$ pale, devoid of marbling, very soft; $5=$ dark, moderately abundant marbling or greater, very firm). At the same time, ultimate $\mathrm{pH}$ values were measured directly using a combined $\mathrm{pH}$ electrode (NWKbinar $\mathrm{pH}, \mathrm{K}-21$, Landsberg, Germany). A $4 \mathrm{~g}$ meat sample $1.5-\mathrm{cm}$-diameter core about $4 \mathrm{~cm}$ long was taken from LM sample, perpendicular to the length of the muscle and suspended in a plastic bag for $24 \mathrm{~h}$ and 7 days at $4^{\circ} \mathrm{C}$. The muscle sample then was reweighed to determine drip loss as a percentage of the original weight. Water holding capacity (WHC) was measured according to the methods of Kauffman et al. (1986). In brief, $0.2 \mathrm{~g}$ sample was pressed at $3000 \mathrm{psi}$ for $3 \mathrm{~min}$ on $125-\mathrm{mm}$ diameter filler paper. The areas of the pressed sample and expressed moisture were delineated and then determined with a digitizing area-line sensor (MT-10S; M.T. Precision Co. Ltd., Tokyo, Japan). A ratio of water:meat areas was calculated, giving a measure of WHC (the smaller ratio indicate the higher the WHC). 2-thiobarbituric acid reactive substances (TBARS) were measured by the method of Witte et al. (1970) and expressed as mg of malonaldehyde (MDA) per kg of muscle. Trichloroacetic acid solution $(20 \% \mathrm{wt} / \mathrm{vol})$ was used for the extraction. A UV absorption spectrophotometry (UV-1201, Shimadzu, Japan) was used for spectrophotometric analysis.

\section{Statistical analyses}

All the data were analysed as a completely randomized design using GLM procedure of SAS (1996). The model included the effects of block (replication) and treatment. Pen served as the experimental unit. Also, the CON diet was compared with HC diets by the polynomial regression (Peterson, 1985) method to determine linear, quadratic and cubic effects. The individual pen served as the unit. Variability of all the data was expressed as standard error (SE) and a probability level of $\mathrm{P}<0.05$ was considered as statistically significant while $\mathrm{P}<0.10$ was considered as a tendency.

\section{RESULTS}

Effects of $\mathrm{HC}$ on growth performance are presented in Table 2. For $0-2$ weeks, there were no significant effects of $\mathrm{HC}$ inclusion on ADFI and gain/feed. There was a slight quadratic effect on ADG $(\mathrm{P}<0.10)$. For 4-8 weeks, ADG was unaffected by $\mathrm{HC}$ and there were no significant quadratic or cubic effects due to 
Table 2. Effect of herbs and coral mineral complex supplementation on growth performance in finishing pigs

\begin{tabular}{|c|c|c|c|c|c|c|c|c|}
\hline \multirow{2}{*}{ Item } & \multirow{2}{*}{ Con $^{1}$} & \multirow{2}{*}{$\mathrm{HC} 0.05^{1}$} & \multirow{2}{*}{$\mathrm{HC} 0.1^{1}$} & \multirow{2}{*}{$\mathrm{HC} 0.2^{1}$} & \multirow{2}{*}{$\mathrm{SE}^{2}$} & \multicolumn{3}{|c|}{ P values for contrasts ${ }^{3}$} \\
\hline & & & & & & $\mathrm{L}$ & $\mathrm{Q}$ & $\mathrm{C}$ \\
\hline \multicolumn{9}{|l|}{$0-2$ weeks } \\
\hline $\mathrm{ADG}, \mathrm{kg}$ & 1.033 & 0.978 & 0.998 & 1.066 & 0.037 & 0.27 & 0.06 & 0.46 \\
\hline ADFI, kg & 2.394 & 2.298 & 2.390 & 2.340 & 0.079 & 0.90 & 0.62 & 0.49 \\
\hline $\mathrm{G} / \mathrm{F}$ & 0.431 & 0.426 & 0.418 & 0.456 & 0.024 & 0.30 & 0.23 & 0.92 \\
\hline \multicolumn{9}{|l|}{ 2-4 weeks } \\
\hline $\mathrm{ADG}, \mathrm{kg}$ & 1.066 & 1.042 & 1.020 & 1.068 & 0.038 & 0.76 & 0.30 & 0.66 \\
\hline ADFI, kg & 2.502 & 2.518 & 2.410 & 2.432 & 0.085 & 0.34 & 0.76 & 0.28 \\
\hline $\mathrm{G} / \mathrm{F}$ & 0.426 & 0.414 & 0.423 & 0.439 & 0.011 & 0.93 & 0.14 & 0.49 \\
\hline \multicolumn{9}{|l|}{ 4-8 weeks } \\
\hline ADG, kg & 1.000 & 0.938 & 1.008 & 1.023 & 0.039 & 0.48 & 0.39 & 0.28 \\
\hline ADFI, kg & 2.552 & 2.486 & 2.444 & 2.378 & 0.063 & $<0.01$ & 0.45 & 0.18 \\
\hline $\mathrm{G} / \mathrm{F}$ & 0.392 & 0.378 & 0.412 & 0.430 & 0.020 & 0.04 & 0.62 & 0.70 \\
\hline \multicolumn{9}{|l|}{ Overall } \\
\hline $\mathrm{ADG}, \mathrm{kg}$ & 1.018 & 0.978 & 1.009 & 1.045 & 0.018 & 0.81 & 0.16 & 0.25 \\
\hline ADFI, kg & 2.502 & 2.450 & 2.423 & 2.390 & 0.045 & 0.02 & 0.30 & 0.38 \\
\hline $\mathrm{G} / \mathrm{F}$ & 0.407 & 0.399 & 0.416 & 0.437 & 0.010 & 0.09 & 0.12 & 0.90 \\
\hline
\end{tabular}

${ }^{1} \mathrm{CON}$, basal diet: $\mathrm{HC} 0.05, \mathrm{CON}+0.05 \% \mathrm{HC}$; $\mathrm{HC} 0.1, \mathrm{CON}+0.1 \% \mathrm{HC}$ : $\mathrm{HC} 0.2, \mathrm{CON}+0.2 \% \mathrm{HC}$, $\mathrm{HC}$ replaced with rice bran in the diet

${ }^{2}$ pooled standard error

${ }^{3}$ P-values for linear (L) quadratic (Q) and cubic (C) effects for the herbs and coral mineral complex

$\mathrm{HC}$ inclusion for ADFI or G/F. However, both ADFI $(\mathrm{P}<0.01)$ and $\mathrm{G} / \mathrm{F}(\mathrm{P}<0.05)$ showed a significant linear effect with $\mathrm{HC}$ inclusion. For the overall period, ADG was unaffected by $\mathrm{HC}$. There was a significant linear response for ADFI $(\mathrm{P}<0.05)$ and a tendency for $\mathrm{G} / \mathrm{F}(\mathrm{P}<0.10)$.

Effects of dietary HC on CTTAD for DM and N are summarized in Table 3. At the end of week 4, both the CTTAD for DM and N was significantly linearly increased with increasing of $\mathrm{HC}$ content in the diets $(\mathrm{P}<0.05)$. However, neither was significantly affected by dietary treatment at the end of week 8 .

Effects of $\mathrm{HC}$ supplementation on blood characteristics in finishing pigs are presented in Table 4. The data suggest that HC did not affect lymphocyte level at any feeding periods. At the final of experiment, IgG level was significant increased ( $\mathrm{L}$ effect; $\mathrm{P}<0.01$ ) as dietary $\mathrm{HC}$ concentration increased. Also, the difference of IgG level between the initial and final of experiment was significantly increased (linear effect; $\mathrm{P}<0.01$ ).

Herbs and coral mineral complex did not affect drip loss, $\mathrm{pH}$ value, WHC and TBARS in current experiment (Table 5). In sensory evaluation, the colour of the pork did not show significant difference among the treatments. However, the marbling of the pork in pigs fed CON diet was higher than for those fed the HC in diets ( $\mathrm{L}$ effect; $\mathrm{P}<0.01$ ). The firmness of pork was significantly linear decreased as 
Table 3. Effect of herbs and coral mineral complex supplementation on coefficient of total tract apparent digestibility (CTTAD) of dry matter (DM) and nitrogen $(\mathrm{N})$ in finishing pigs

\begin{tabular}{lcccccccc}
\hline Item & \multirow{2}{*}{ Con $^{1}$} & \multirow{2}{*}{$\mathrm{HC}^{2} 05^{1}$} & \multirow{2}{*}{$\mathrm{HC} 0.1^{1}$} & \multirow{2}{*}{$\mathrm{HC} 0.2^{1}$} & $\mathrm{SE}^{2}$ & \multicolumn{3}{c}{$\mathrm{P}$ values for contrasts } \\
\cline { 6 - 9 }
\end{tabular}

$1,2,3$ explanation see Table 2

Table 4. Effect of herbs and coral mineral complex supplementation on blood characteristics in finishing pigs

\begin{tabular}{|c|c|c|c|c|c|c|c|c|}
\hline \multirow{2}{*}{ Item } & \multirow{2}{*}{$\operatorname{Con}^{1}$} & \multirow{2}{*}{$\mathrm{HC} 0.05^{1}$} & \multirow{2}{*}{$\mathrm{HC} 0.1^{1}$} & \multirow{2}{*}{$\mathrm{HC} 0.2^{1}$} & \multirow{2}{*}{$\mathrm{SE}^{2}$} & \multicolumn{3}{|c|}{$\mathrm{P}$ values for contrasts } \\
\hline & & & & & & $\mathrm{L}$ & $\mathrm{Q}$ & $\mathrm{C}$ \\
\hline \multicolumn{2}{|l|}{ Cortisol, $\mu g / d l$} & 4.05 & 4.10 & 3.72 & 1.59 & 0.89 & 0.84 & 0.98 \\
\hline final & 3.14 & 2.48 & 2.36 & 2.24 & 0.32 & 0.07 & 0.41 & 0.71 \\
\hline difference & -1.06 & -1.57 & -1.74 & -1.48 & 1.62 & 0.62 & 0.90 & 0.81 \\
\hline \multicolumn{9}{|l|}{$\operatorname{IgG}, m g / d l$} \\
\hline initial & 769.60 & 841.60 & 750.20 & 936.80 & 86.90 & 0.31 & 0.52 & 0.28 \\
\hline final & 795.80 & 882.40 & 1040.60 & 1312.00 & 78.80 & $<0.01$ & 0.28 & 0.90 \\
\hline difference & 26.20 & 40.80 & 290.40 & 375.20 & 81.76 & $<0.01$ & 0.68 & 0.30 \\
\hline \multicolumn{9}{|l|}{ Lymphocyte, \% } \\
\hline initial & 43.20 & 44.60 & 40.20 & 44.20 & 3.01 & 0.95 & 0.78 & 0.49 \\
\hline final & 63.00 & 60.00 & 55.80 & 61.20 & 4.22 & 0.88 & 0.64 & 0.46 \\
\hline difference & 19.80 & 15.40 & 15.60 & 17.00 & 7.34 & 0.90 & 0.92 & 0.98 \\
\hline
\end{tabular}

$1,2,3$ explanation see Table 2

Table 5. Effect of herbs and coral mineral complex supplementation on meat quality in finishing pigs

\begin{tabular}{|c|c|c|c|c|c|c|c|c|}
\hline \multirow{2}{*}{ Item } & \multirow{2}{*}{ Con $^{1}$} & \multirow{2}{*}{$\mathrm{HC} 0.05^{1}$} & \multirow{2}{*}{$\mathrm{HC} 0.1^{1}$} & \multirow{2}{*}{$\mathrm{HC} 0.2^{1}$} & \multirow{2}{*}{$\mathrm{SE}^{2}$} & \multicolumn{3}{|c|}{$\mathrm{P}_{\text {values for contrasts }}{ }^{3}$} \\
\hline & & & & & & $\mathrm{L}$ & Q & $\mathrm{C}$ \\
\hline \multicolumn{9}{|l|}{ Sensory evaluation } \\
\hline colo & 2.95 & 2.90 & 2.85 & 2.72 & 0.12 & 0.18 & 0.74 & 0.88 \\
\hline marbling & 2. & 1.98 & 2.0 & 1.7 & 0.07 & $<0.01$ & 0.33 & 0.10 \\
\hline firmness & 2.28 & 1.76 & 1.83 & 1.57 & 0.10 & $<0.01$ & 0.22 & 0.06 \\
\hline \multicolumn{9}{|l|}{ Drip loss, $\%$} \\
\hline 1 day & 2.83 & 3.93 & 1.52 & 3.67 & 0.93 & 0.97 & 0.56 & 0.11 \\
\hline 7 days & 8.30 & 7.96 & 5.65 & 7.35 & 1.28 & 0.42 & 0.33 & 0.48 \\
\hline $\mathrm{pH}$ & 5.65 & 5.66 & 5.68 & 5.60 & 0.05 & 0.85 & 0.28 & 0.68 \\
\hline WHC, $\%$ & 33.36 & 38.36 & 42.90 & 38.08 & 4.67 & 0.37 & 0.30 & 0.70 \\
\hline TBARS, mgMA/kg & 0.129 & 0.110 & 0.110 & 0.098 & 0.012 & 0.18 & 0.78 & 0.66 \\
\hline
\end{tabular}

1,2,3 explanation see Table 2

dietary $\mathrm{HC}$ concentration increased $(\mathrm{P}<0.01)$. Also, cubic effects were observed in marbling and firmness of pork $(\mathrm{P}=0.10 ; \mathrm{P}<0.10)$. 


\section{DISCUSSION}

In the present study, during week 4 to 8 and overall the period, gain/feed was linear increased with an increase of $\mathrm{HC}$ level. This result agreed with Park et al. (2000) who using 0.4 and $0.8 \%$ tranquilizing herb-mix diets fed pigs observed significant improvements on gain/feed from their growth trials, and they explained this improvement was due to the herbs having positive effect on growth hormone. However, our data showed ADG was not affected by the supplement of HC, but ADFI was decreased. Reasonable explanation for the lower ADFI of the pigs fed HC supplemented diets is tranquilizing effect of herbs reducing the spontaneous physical activity of pigs. Physical activity influences heat production, which can cause the additional expenditure of energy. Close and Poorman (1993) calculated that the additional expenditure of energy by growing pigs for walking was $2.80 \mathrm{KJ}$ of $\mathrm{ME} / \mathrm{kg}$ of $\mathrm{BW}$ for each kilometer. Therefore, pigs fed HC supplemented diets may be have a lower energy requirement compared with CON treatment, which may lead to the decline of ADFI.

The active components of the herbal product, cortex mori, semen Plantaginis, Rhizoma Acori tatarinowii and herb Capsellae, are known for their effects of improvement appetite, antiinflammatory for reducing diarrhoea, promoting digestive juice secretion and strengthening the stomach, respectively (Lei, 1995). All of the actions aforementioned can results in the better digestibility of DM and $\mathrm{N}$ at 4 week. Another reasonable explain for the improvement of CTTAD at the end of week 4 is that coral minerals are in a natural balance with all of the minerals required, especially the trace minerals, to support each mineral in its designated role. It can make sure the pig's digestive juice and enzyme well-balanced production and secretion so as to ensure better digestibility were obtained (Mcvitamins, 2000). The reason why HC supplement did not affecting the CTTAD for DM and N at the end of week 8 can not be explained from current result, further investigations are needed to determine if this is a real or spurious result.

The concentration of cortisol in plasma can be regarded as a criterion to reflect stress intensity (Webel et al., 1997). The linear decline of cortisol level in plasma in $\mathrm{HC}$ treatments at the end of experiment may be caused by the compositions of herbs (semen Zizyphi Spinosae, pollen pini and cortex mori), which are known for their tranquilizing and sedative effect (Lei, 1995; Choi, 2007). Inconsistently, Peeters et al. (2006) found no difference in the decreases or increases of cortisol between control and herb-supplemented group after a stress vibration test with pigs. However, Peeters et al. (2005) found that pigs were visually calmer than control pigs in vibrating experimental research after supplementation magnesium. Thus, the additional magnesium supplement in diets (3\% magnesium in HC) might cause some positive effects on reducing stress in pigs. Cortisol produced during stress situations may suppress the body's immune response (Coe, 
1997), and higher level of cortisol in the bloodstream had been shown to have negative effects, such as lowered immunity (Suzanne and Gregory, 2004). The immunomodulatory effect of semen Plantaginis and radix Achyranthis bidentatae were shown in many previous researches (e.g., Chiang et al., 2003). For the above reasons, IgG level was significantly increased with addition HC level. Moreover, coral mineral supplied enough trace mineral, such as selenium and zinc, which have positive effect on immunity, is another explanation to improve the IgG level in pig. In the current study, $\mathrm{HC}$ did not affect lymphocyte level in blood. Our data are different from other research, which has shown, that porcine immune cell with cortisol suppresses lymphocyte proliferation (Salak et al., 1993). This may be due to cortisol level just showed a slight different, which is not enough to cause the lymphocyte proliferation reducing, among the treatments in our experiment.

In the current study, $\mathrm{HC}$ did not affect colour, drip loss, $\mathrm{pH}$ and WHC. Our data were consistent with the results by Peeters et al. (2006), who reported no effect of herb-supplemented group in the diet of pigs on $\mathrm{pH}$ and WHC in longissimus muscle. No more comparisons with other studies could be made because investigations about the use of herbal products in relation to meat quality are not reported yet. The TBARS was decreased numerically in HC treatments compared with CON treatment in current study. Anti-oxidative effect of pollen pini in herb mix may be causing this numerical decline of TBARS. Bao et al. (2006) reported that the active antioxidant components of the pollen pini are known for vitamin $\mathrm{E}$, carotene and Se, which were widely known for inhibiting the lipid in vitro and protein peroxidation. They suggested the further mechanism may be due to pollen pini could improve the activity of SOD and free radical scavenging effect. Similarly, Guo et al. (2006) suggested that high level of vitamin E supplementation had a beneficial effect on the oxidative stability of pork as indicated by TBARS values. Surprisingly, marbling and firmness of sensory evaluation were linearly decreased with the increase of HC level. The decline of marbling scale may be caused by the reduction of physical activity have some negative effect on intramuscular fat deposition. The exact mechanisms underlying these abnormalities reduction of firmness are not known from current experiment. Understanding these mechanisms should prove useful in the quest for unraveling the complex machinery controlling pork quality development.

\section{IMPLICATIONS}

Under the conditions of present experiment, the benefit on cortisol and IgG level in serum and the greater gain/feed have been obtained with the supplement of HC in diets. However, unexpected negative effect of meat quality was detected, which is necessary to be further investigated to explain the underlying mechanism. The 
further research should be continued with testing single herbs or coral minerals effects. Also ethological research should be conducted to investigate whether sedative and tranquilizing herbs supplementation in pig diets can lead to a decline of spontaneous motor activity. It may be explain some underlying mechanism in this experiment.

\section{REFERENCES}

AOAC, 1995. Association of Official Analytical Chemists, Official Method of Analysis. $16^{\text {th }}$ Edition. Washington, DC

Bao S.F., Cong Q., Illig J., Schempp H., Elstner E.F., 2006. Study on the antioxidant properties and mechanism of pollen and needle extracts from Pinus massoniana in lipophilic model system Acad. J. Pla Postgrad. Med. School. 27(5)

Coe C.L., 1997. Stress decreases lymphocyte cytolytic activity in the young monkey even after blockade of steroied and opiate hormone receptors. Develop. Psychobiol. 30, 1-10

Chiang L.C., Chiang W., Chang M.Y., Lin C.C., 2003. In vitro cytotoxic, antiviral and immunomodulatory effects of Plantago major and Plantago asiatica. Amer J. Chin. Med. 31, 225-234

Choi E.M., 2007. Antinociceptive and antiinflammatory activities of pine (Pinus densiflora) pollen extract. Phytother. Res. 21, 471-475

Close W.H., Poorman P.K., 1993. Outdoor pigs - their nutrient requirements, appetite and enviromental responses In: P.C. Garnsworthy, D.J.A. Cloe (Editors). Recent Advances in Animal Nutrition. Loughborough, Nottingham University Press, pp. 175-196

Fenton T.W., Fenton M., 1979. An improved method for chromic oxide determination in feed and feces. Can. J. Anim. Sci. 59, 631-634

Guo Q., Richert B.T., Burgess J.R., Webel D.M., Orr D.E., Blair M., Fitzner G.E., Hall D.D., Grant A.L., Gerrard D.E., 2006. Effects of dietary vitamin E and fat supplementation on pork quality. J. Anim. Sci. 84, 3089-3099

Jian J.C., Wu Z.H., 2003. Effects of Chinese medicine on nonspecific immunity and disease resistance of large yellow croaker, Pseudosiaena crocea (Richardson). Aquaculture 218, 1-9

Kauffman R.G., Eikelenboom G., van der Wal P.G., Engel B., Zaar M., 1986. A comparison of methods to estimate waterholding capacity in post-rigor porcine muscle. Meat Sci. 18, 307-322

Kietzmann M., Jablonski H., 1985. On the blocking of stress by magnesium-aspartate hydrochloride in the pig. Prakt. Tierarzt. 66, 328-335

Lei Z.Q. (Editor), 1995. Expectorant, Antitussive and Antiasthmatic Effects Medicine (Cortex Mori), pp. 244-245; Orifice-Opening Medicine (Rhizoma Acori Tatarinowii), pp. 273; Li Shui Tong Lin Medicine (Herba Capsellae), pp. 138; Sedative, Hypnotic and Hypoxia-Resisting Effects Medicine (Semen Ziziphi Spinosae). pp. 252-253. Herbology. Shanghai

Mahan D.C., Cline T.R., Richert B., 1999. Effects of dietary levels of selenium-enriched yeast and sodium selenite as selenium sources fed to growing-finishing pigs on performance, tissue selenium, serum glutathione peroxidase activity, carcass characteristics and loin quality. J. Anim. Sci. 77, 2172-2179

Mcvitamins (A Nutritional Education Site on Vitamins and Food), 2000. Site Index (homepage on the Internet). Site Index for Coral Calcium; (cited 28 December 2006). Available from URL: http://www.mcvitamins.com/Index-page.htm 
Mdidea, 1997. Catalog and Products (homepage on the Internet). Catalog \& Products for Herb Remedy and Natural Formula; "The Spine Date Seed or Chinese Sleeping Elixir,What is Semen Ziziphi Spinosa?” (cited 20 March 2007). Available from URL: http://www.mdidea.com/ products/new/new014.html

NRC, 1998. Nutrient Requirements of Swine. National Research Council. 10 $0^{\text {th }}$ Edition. National Academy Press. Washington, DC

NPPC, 1991. Pork Composition and Quality Assessment Procedures. National Pork Production Council. Des Moines, IA

Park K.M., Han Y.K., Park K.W., 2000. Effects of herb-Mix supplementation on the growth performance and serum growth hormone in weaned pigs. Asian-Austr. J. Anim. Sci. 13, 791794

Peterson R.G.., 1985. Desigen and Analysis of Experiments. Marcel Dekker, Inc. NY

Peeters E., Driessen B., Steegmans R., Henot D., Geers R., 2006. Effect of supplemental tryptophan, vitamin $\mathrm{E}$, and a herbal product on stress responses and pork quality. J. Anim. Sci. 84, 18271838

Peeters E., Neyt A., Beckers F., De Smet S., Aubert A.E., Geers R., 2005. Influence of supplemental magnesium, tryptophan, vitamin $\mathrm{C}$, and vitamin $\mathrm{E}$ on stress responses of pigs to vibration. J. Anim. Sci. 83, 1568-1580

Salak J.L., McGlone J.J., Lyte M., 1993. Effects of in vitro adrenocorticotrophic hormone, cortisol, and human recombinant interleukin-2 on porcine neutrophil migration and luminol-dependent chemiluminescence. Vet. Immunol. Immunopathol. 39, 327-337

SAS, 1996. SAS User's Guide. Release 6.12 Edition. SAS Institute Inc. Cary, NC

Suzanne C.S., Gregory E.M., 2004. Psychological stress and the human immune system: a metaanalytic study of 30 years of inquiry. Psychol. Bull. 130, 601-630

Warriss P.D. (Editor), 1993. Ante-mortem factors which influence carcass shrinkage and meat quality. Proceedings of 39th International Congress of Meat Science and Technology. Calgary (Canada), p. 51

Webel D.M., Finck B.N., Baker D.H., Johnson R.W., 1997. Time course of increased plasma cytokines, cortisol, and urea nitrogen in pigs following intraperitoneal injection of lipopolysaccharide. J. Anim. Sci. 75, 1514-1520

Witte V.C., Krause G.J., Bailey M.E., 1970. A new extraction method for determining 2-thiobarbituric acid values of pork and beef during storage. J. Food Sci. 35, 582-585

Zheng W., Wang S., 2001. Antioxidant activity and phenolic composition in selected herbs. J. Agr. Food Chem. 49, 5165-5170 